\title{
PATTERN OF ILLICIT DRUG USE AMONG ADULTS ATTENDING FAMILY MEDICINE CENTER OF FANARAH VILLAGE IN ISMAILIA CITY, EGYPT.
}

\author{
Safaa M. EL-Zoghby*, Nadia M. Mansour*, Nahed A. Eldahshan*, Manal S. Fawzy**, \\ Abeer M. Hagras*** \\ *Family Medicine Department, ${ }^{* *}$ Medical Biochemistry Department, ${ }^{* * *}$ Forensic Medicine \\ and Clinical Toxicology Department, Faculty of Medicine, Suez Canal University, Egypt
}

Corresponding author:

Abeer M. Hagres:

E-mail: abeerhagras@gmail.com

Tel: +(2)-01224580446

Background: Pattern of drug abuse and dependence are different between countries. This should be considered while planning preventive and therapeutic strategies for optimal outcome achievement. Aim: To identify and manage drug abuse phenomenon among adults attending Family Medicine Center of Fanarah Village in Ismailia city, Egypt. Pateints and methods: A cross sectional descriptive study was carried out on 243 adults, $60.9 \%$ male and $39.1 \%$ female aged between more than 18 to 65 years old. They attending Fanarah primary health care center, Ismailia city, Egypt, in the period from the first of June 2013 to the end of December, 2014. Participants were structured interviewed and asked about the socio-demographic and drug history data. An anonymous, designed questionnaire was fulfilled by the researcher for each participant and the confidentiality has been preserved. Drugs were estimated in the urine samples of all participants using thin-layer chromatography (TLC) followed by high performance liquid chromatography (HPLC) methods. Results: The prevalence of illicit drug use was $44.8 \%$. Male gender represented the majority of illicit drug users (32.9\%) Vs female users which represented $(11.9 \%)$ and the majority of drug abusers started taking drugs for the first time at age 15-24 years old. The distribution of the most commonly abused drugs among abusers was as follows: Bango 11.1\%, Hashish 8.2\% and tramadol 9.8\%. Abusing Heroin, Cocaine and Valium, was less prevalent among the studied adults $(1.2 \%, 0.8 \%$ and $1.2 \%$, respectively). Conclusions: Illicit drug use among adults in the study population starts in younger ages. Cannabis is still the most widely abused one, although tramadol becomes an increasingly alarming phenomenon.

Keywords: Drug abuse, adults, primary health care, Ismailia, Egypt.

\section{INTRODUCTION}

The World Health Organization (WHO), following the International Classification of Diseases, defines the drug use problem as "harmful drug use" and "drug dependence". Harmful drug use is defined by "clear evidence that the substance use is responsible for physical and psychological harm" (WHO, 2013). Illicit drug use includes the non-medical use of a variety of drugs that are prohibited by 
international law. These drugs include: cannabis, cocaine, heroin and other opioids, amphetamine type stimulants and 3, 4-methylenedioxymethamphetamine (MDMA) that is also known as ecstasy (Darke et al., 2006).

The effect of substance abuse results in negative outcomes for both individuals and society. For example, the total overall costs of substance abuse in the US, including loss of the productivity as well as costs related to health and crime, have been estimated to exceed $\$ 416$ billion a year for illicit drugs and alcohol (Degenhardt \& Hall, 2012). The health consequences of substance abuse are many, including; cardiovascular disease, hepatitis $\mathrm{B}$ and $\mathrm{C}$, the human immunodeficiency virus/acquired immunodeficiency syndrome (HIV/AIDS) (Khalsa et al., 2008), liver diseases, lung disease, cancer, miscarriage and stillbirth among pregnant women birth defects among children (Shankaran et al., 2007), stroke, unintentional injuries, violence, premature death, in addition to psychiatric disorders, including dementia and mental disorders (Charlson et al., 2015).

The use of psychoactive substances is not a new phenomenon. They have been consumed throughout history. Yet the current drug problem is characterized by a concentration of illicit drug use among youth as reported by the United Nations Office on Drugs and Crime (UNODC, 2012). Initiation of drug use mostly begins with one or more of the following in the early teens: volatile substances, cannabis or alcohol. Ecstasy and other dance drugs are often tried in the late teens, while the initiation of opiates or cocaine typically occurs in the early twenties (McIntosh et al., 2006).

Egypt and other Arab region countries experienced the drug use phenomenon for centuries. In Egypt substance use disorders is one of the serious problems that worry the Egyptian government, as it deals with young people within the age of work and productivity. From the second half of the 1990s, Cannabis became prevalent in the form of Bango (Fawzi, 2011), however, recently a raising alarming phenomenon of tramadol abuse has been greatly noted. Although the issue of drug abuse is not a newly introduced issue of Egyptian society, but the wide range of usage and illegal transactions associated with tramadol abuse makes it the most easily accessible and readily provided drug at cheap cost (Bassiony et al., 2015).

Although worldwide prevalence is high, it is noted that illicit drug use remains vastly underestimated because of the inherent difficulty in gathering data. Family physicians have a key role in finding those who may use illicit drugs as they are the first station of medical contact for most patients and they can build a good and ongoing relationship with them that is built on trust and confidentiality, which makes the patient reveal their illicit drug use without the fear of the stigma.

The current research was conducted to find out the prevalence of illicit drug use among adults attending the family medicine center of Suez Canal University (SCU) hospital in Fanarah village, Ismailia governorate, Egypt, in an attempt to highlight the size of the problem in the current area that characterized by its geographic location as a potential transit point between major illicit drug production 
areas in Asia and European markets, for subsequent potential implementation of educational and preventive strategies by the community authority.

\section{PATIENTS AND METHODS}

The total number of adults attending the family medicine center of Fanarah village during the period of the study was 681 adults. A cross sectional descriptive study was carried out on 243 (35.6\%) adults, (139 males and 104 females). They were recruited from the total number attending Fanarah family medicine center, Ismailia city, Egypt, during the period from the first of June 2013 until the end of December 2014. Fanarah primary health care center is working under the control of Faculty of Medicine, Suez Canal University, it gives distinguished service to people from both Faid City (urban area) and fanarah village (rural area). The study protocol conducted in compliance with the Helsinki Declaration and approved by the ethical committee of SCU. The inclusion criteria were adults of both sex (18- 64 years old), attending family practice center clinic in the Fanarah village in Ismailia city and accept to participate in the study. While those who were using non-steroidal anti-inflammatory drugs, taking drugs in according to physician's prescription, and those who refused to participate in the study, were excluded. Participants were interviewed and an anonymous semistructured researchers' designed questionnaire was presented to each participant and fulfilled by the researcher after an informed written consent was obtained. Reassuring the participants about the confidentiality of the questionnaires' contents was confirmed. Questionnaires were composed of two parts: the first, contained socio-demographic data of the participants, including: age, gender, residence, marital status, occupation, income sufficiency and the educational level. The second part included queries about a history of drug use and, type of used drug (s), recent use of drugs, the first time of taking drugs, reasons of using drugs, effects on the participant's life.

Detection of abused drugs in the urine samples

Each participant gave about $30 \mathrm{ml}$ of random urine sample in a sterile plastic container without any added preservative. Each sample has been labeled with application of all precautions to prevent sample interchange. Subsequently, the containers have been collected and transported in an ice bag to the Toxicology laboratory of Forensic Medicine and Clinical Toxicology Department, SCU, Ismailia, for drug detection using thin-layer chromatography (TLC) as a screening method. High performance liquid chromatography (HPLC) was subsequently carried out on the Agilent1260 infinity set (Agilent Technology, USA) at Forensic Medicine and Clinical Toxicology Department, Mansoura University, Egypt, for positive samples by TLC as a confirmatory test. All samples were tested according to the manufacturer's instructions.

The urine samples were pre-treated before being placed on the TLC Silica gel $60 \mathrm{~F}_{254}$ plates (EMD Millipore Co., Germany) by transferring it from an aqueous to an organic phase and concentrating it according to Nickerson, (2011). Ten micro liters 
have been spotted onto the plate, and mixed with an appropriate calorimetric reagent (i.e Marquis, Liebermann's, Mandelin's, Vitali's, Beam, Millons or Frohde's reagents). The results of the test have been compared with a reference standard for Parkinol, Rohypnol, Morphine, Cannabinoid, Barbiturate, and Amphetamine tested under the same conditions (Figure 1A and B) (Solomon et al., 2010).

\section{Statistical analysis}

General statistical analyses were performed using the Statistical Package for Social Science (SPSS) software version 16 (IBM Corporation, Armonk, NY, USA). The categorical data were expressed as frequencies (percentages) and were compared using the standard Pearson Chi-square test and Fishers' exact test when appropriate. A twotailed $\mathrm{P} \quad<0.05$ was considered significant.

\section{RESULTS}

A total of 243 adults completed the current study. In fulfilling the questionnaires, $100(41.1 \%)$ of the total participants mentioned their abused drug, and nine participants more than 100 cases (109 adults) had positive results for drugs use documented by TLC and HPLC investigations (Fig. 13). Most of the adults (41.1\%) mentioned their abuser to drugs in questionnaires, were aged from 19 to 25 years $(14.8 \%)$ with male predominance $(29.2 \%)$. Those residents in urban areas represent 70 adults $(29.0 \%)$, most of them were married $(21.3 \%)$ and highly educated $(24.3 \%)$ with inadequate income $(25.9 \%)$. The adults who denied their illicit drug use in questionnaires $(n=9)$, were single males, of whom $2.8 \%$ were educated till preparatory school and had skilled jobs, and $3.3 \%$ had an adequate income, 11-nor- $\Delta-9$ tetrahydrocannebinol-9-carboxylic acid (THC-COOH) were detected among four participants, tramadol was detected among three participants and parkinol was detected among two participants of them and confirmed by HPLC. On the other hand, 134 adults did not abuse illicit drugs, most of them aged 18 years $(18.5 \%), 27.9 \%$ are males, most of them are married $(30.4 \%)$, and highly educated $(24.3 \%)$, with skilled jobs $(32.1 \%)$, and $39.9 \%$ had an inadequate income (Table 1). Comparison of the socio-demographic characteristics between drug abusers and non-abusers among the study participants has revealed a statistically significant difference between both groups regarding the participant gender and income (Table 1)

The study findings illustrated that cannabis was used in the form of Bango and Hashish by 51 cases $(21.1 \%)$ of the total participants, tramadol users represent 27 cases (11.1\%) followed by Seconal and Parkinol users which represented 10 cases $(4.1 \%)$ and 8 cases $(3.3 \%)$, respectively. While heroin and Valium users represented $1.2 \%$ of study participants and finally cocaine represents the least one $(0.8 \%)$ abused among participants (Fig. 4).

Concerning bango, hashish and tramadol abuse among adult attending family medicine center of Fanarah village in Ismailia city and mentioned their abuse in questionnaires, 27 participants $(11.1 \%)$ were smoke Bango, 24 cases $(88.9 \%)$ of them used this agent 40 times or more during their lifetime, 20 cases $(74.1 \%)$ used this agent 40 times or more in the last 12 months, 15 cases $(55.6 \%)$ took their 
last dose a day before fulfill the questionnaire and 16 cases $(59.3 \%)$ use Bango for the first time at the age between 15-24 years old. While Hashish was used by 20 cases $(8.2 \%)$ of all participants, most of them $(55.0 \%)$ took it through smoking, while 16 cases $(80.0 \%)$ of them used this agent 40 times or more during their lifetime, and 13 cases $(65.0 \%)$ used it 40 times or more in the last 12 months, 5 cases $(25.0 \%)$ took their last dose a day before fulfill the questionnaire and the age at first time of its' use was between $15-24$ years in $13(65.0 \%)$ of cases. Otherwise, 24 cases ingested tramadol, 20 cases of them $(83.4 \%)$ ingested it 40 times or more during their lifetime, 15 cases $(62.6 \%)$ used this agent 40 times or more in the last 12 months, 10 cases $(41.6 \%)$ took their last dose a day before fulfill the questionnaire and 15 cases (62. 6\%) use tramadol for the first time at the age between 25-34 years old (Table 2).

Regarding Cocaine and Heroin abuse among study participants, inhaled cocaine was used by just 2 cases $(0.82 \%)$ in whom their last dose administration was more than one year ago and one of the two cases took his first dose at the age above 35 years old. Otherwise, 3 cases $(1.23 \%)$ inhaled heroin, in whom two cases $(66.6 \%)$ had the last dose of administration more than one year ago and the first time of use was at 25-35 years old (Table 3 ).

Of 243 participants, six cases (2.46\%) used Parkinol by ingestion, 3 cases $(50.0 \%)$ of them used it for more than 10 times during his/her lifetime, 5 of them $(83.3 \%)$ did not use this agent in the last 12 months, the last dose of this agent was a week ago in one participant, the age at the first time of use was between 15-24 years in 3 cases
(50.0\%) and was between 25-34 years in the other 3 cases, while Rohypnol was used by 5 cases $(2.1 \%)$ of 243 participants through ingestion, two cases $(40.0 \%)$ of them use it for more than 10 times during his/her lifetime and 3 cases $(60.0 \%)$ of them did not use this agent in the last 12 months, the last dose of taking Rohypnol was a day before fulfillment the questionnaire in one participant, and the age of the first time of use of this drug was between $15-24$ years in 3 cases $(60.0 \%)$ of them. Regarding using Seconal 10 participants $(4.1 \%)$ of 243 mentioned that they used it by ingestion, 8 cases $(80.0 \%)$ of them used it for more than 10 times during his/her lifetime, 5 cases $(50.0 \%)$ of them used it more than 10 times in the last 12 months and the last dose of taking Seconal was more than a year in the other 5 cases $(50.0 \%)$, the age at the first time of using this drug was between 15-24 years in 5 cases. On the otherwise Valium was used by 3 $(1.23 \%)$ of 243 participants, two of them $(66.7 \%)$ used it for more than 10 times during his/her lifetime, and one case $(33.3 \%)$ of them used it more than 10 times in the last 12 months and the last dose of taking Valium was a day before fulfilling the questioner in one $(33.3 \%)$ case and the age at the first time of using this drug was between 15-24 years in 3 cases (Table 4).

The current results showed that, among 100 adult abusers, according to filled questionnaires, $73 \%$ are current smokers, while $32.0 \%$ were alcohol users, also $59.0 \%$ of abusers had family member using drugs, and $53.0 \%$ of them were introduced drug for the first time through friends, with $72.0 \%$ frequently spend time with friends who use drugs, $47.0 \%$ mentioned that, drug use never affect their ability to cope 
with school or work, while $56.0 \%$ reported that drug use never leads to induce problems with others. Otherwise, the most common reason for using drugs among abusers was its' usage by one of the parents or family members $(36.0 \%)$, followed by the bad fellowship or just for fun $(12.0 \%)$; considering it as a way to get more pleasure (for instance in sexual relation or other activities) (Table 5).

Table (1): Socio-demographic characteristics of the study cases attending the family medicine center of Fanarah Village in Ismailia city regarding drug abuse $(n=243)$.

\begin{tabular}{|c|c|c|c|c|c|}
\hline \multicolumn{2}{|c|}{$\begin{array}{l}\text { Socio-demographic } \\
\text { characteristics }\end{array}$} & $\begin{array}{c}\text { Adults' abuse } \\
\text { mentioned their } \\
\text { illicit drug use in } \\
\text { questionnaires } \\
(n=100)\end{array}$ & $\begin{array}{l}\text { Adults' abuse which } \\
\text { were positive by } \\
\text { analysis and deny } \\
\text { the use of drugs } \\
(n=9)\end{array}$ & $\begin{array}{l}\text { Adults did } \\
\text { not abuse } \\
\text { illicit drugs } \\
\quad(n=134)\end{array}$ & 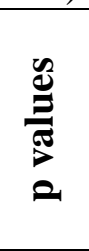 \\
\hline \multirow{4}{*}{$\begin{array}{l}\text { Age } \\
\text { (years) }\end{array}$} & $18-$ & $32(13.2)$ & $6(2.5)$ & $45(18.5)$ & \multirow[t]{4}{*}{.321} \\
\hline & $25-19$ & $36(14.8)$ & $3(1.2)$ & $38(15.6)$ & \\
\hline & $35-26$ & $22(9.1)$ & 0 & $29(11.9)$ & \\
\hline & $>35$ & $10(4.1)$ & $\mathbf{0}$ & $22(9.1)$ & \\
\hline \multirow[t]{2}{*}{ Gender } & Male & $71(29.2)$ & $9(3.7)$ & $68(27.9)$ & \multirow[t]{2}{*}{.000} \\
\hline & Female & $29(11.9)$ & $\mathbf{0}$ & $66(27.1)$ & \\
\hline \multirow[t]{2}{*}{ Residence } & Urban & $70(29.0)$ & $4(1.6)$ & $97(39.9)$ & \multirow[t]{2}{*}{.371} \\
\hline & Rural & $30(12.3)$ & $5(2.1)$ & $37(15.2)$ & \\
\hline \multirow{4}{*}{$\begin{array}{l}\text { Marital } \\
\text { Status }\end{array}$} & Single & $35(14.4)$ & $9(3.7)$ & $35(14.4)$ & \multirow[t]{4}{*}{.106} \\
\hline & Married & $52(21.3)$ & 0 & $74(30.4)$ & \\
\hline & Divorced & $4(1.6)$ & $\mathbf{0}$ & $8(3.3)$ & \\
\hline & Widow & $9(3.7)$ & $\mathbf{0}$ & $17(6.9)$ & \\
\hline \multirow[t]{4}{*}{ Education } & $\begin{array}{l}\text { Illiterate/ } \\
\text { uneducated }\end{array}$ & $15(6.2)$ & $\mathbf{0}$ & $30(12.3)$ & \multirow[t]{4}{*}{.164} \\
\hline & $1^{\text {ry }}$ school & $6(2.5)$ & $\mathbf{0}$ & $12(4.9)$ & \\
\hline & $\begin{array}{l}\text { Preparatory } \\
\text { school }\end{array}$ & $20(8.2)$ & $7(2.8)$ & $33(13.5)$ & \\
\hline & $\begin{array}{l}\text { High school and } \\
\text { University }\end{array}$ & $59(24.3)$ & $2(0.8)$ & $59(24.3)$ & \\
\hline \multirow{3}{*}{$\begin{array}{l}\text { Employm } \\
\text { ent Status }\end{array}$} & Unemployed & $15(6.2)$ & $2(0.8)$ & $30(12.3)$ & \multirow[t]{3}{*}{.360} \\
\hline & Skilled job & $59(24.3)$ & $7(2.8)$ & $78(32.1)$ & \\
\hline & Specialized job & $26(10.7)$ & 0 & $26(10.6)$ & \\
\hline \multirow{2}{*}{$\begin{array}{l}\text { average } \\
\text { Income/ } \\
\text { month }\end{array}$} & Inadequate & $63(25.9)$ & $1(0.4)$ & 97 (39.9) & \multirow[t]{2}{*}{.025} \\
\hline & Adequate & 37 (15.2) & 8 (3.3) & $37(15.2)$ & \\
\hline
\end{tabular}

- Data are expressed as n (\% of the total participants). Chi square or Fisher's exact tests were used for comparison between study Drug abusers $(n=109)$ and non-abusers $(n=134)$. Significant $P$ value $<.05$.

- Skilled jobs mean manual workers in factories or free workers like plumber, electrician, fisher man and welder. (In case of free work they may be Day-laborer).

- Average Income/month is according to the participants' opinion. 


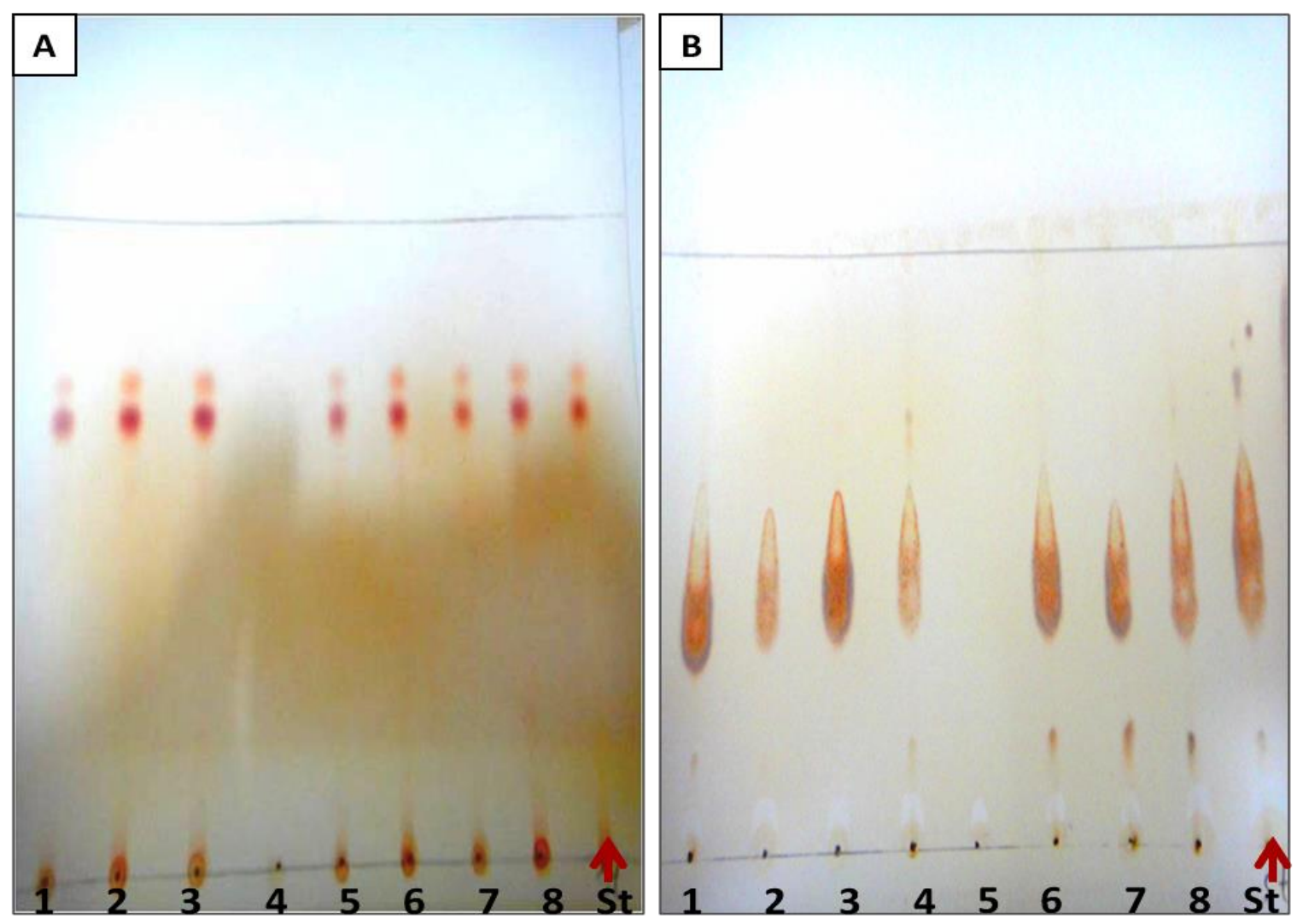

Figure (1): Chromatogram of thin layer chromatography (TLC) testing for: (A) Cannabis, and (B) Tramadol. Stationary phase: TLC Silica gel $60 \mathrm{~F}_{254}$, Mobile phase: acetic acid:n-buthanol:water (1:4:1) for Cannabis and Chloroform: Ethanol (7:3 v/v) for Tremadol. Lanes: (A1-3, A5-8, B1-4, B6-8): participant samples; Lane: (A4 and B5) blank; St: standard. 
Data File C: \CHEM32\1\DATA \CANNABIS \TRIAL000041.D

Sample Name: cannabislmcg

Acq. Operator : manar

Acq. Instrument : 1260 AGILENT HPLC

Injection Date : 29/09/2014 11:37:36 *

Location : Vial 1

Acq. Method

: C: \CHEM32\1\METHODS \CANNABIS ISOCRATIC.M

Last changed

: 29/09/2014 10:39:44 w by manar

(modified after loading)

Analysis Method : C: \CHEM32\1\METHODS\CANNABIS ISOCRATIC.M

Last changed : 29/09/2014 11:52:41 w by manar

(modified after loading)



Figure (2): Confirmation of positive TLC results was accomplished by an HPLC technique for 11-nor- $\Delta$-9-tetrahydrocannebinol-9-carboxylic acid (THC-COOH). It was separated and elute from the column at 5.48 minutes [retention time]. 
Data File C: \CHEM32\1\DATA \MANAR\TRAM000018.D

Sample Name: tramadol 1
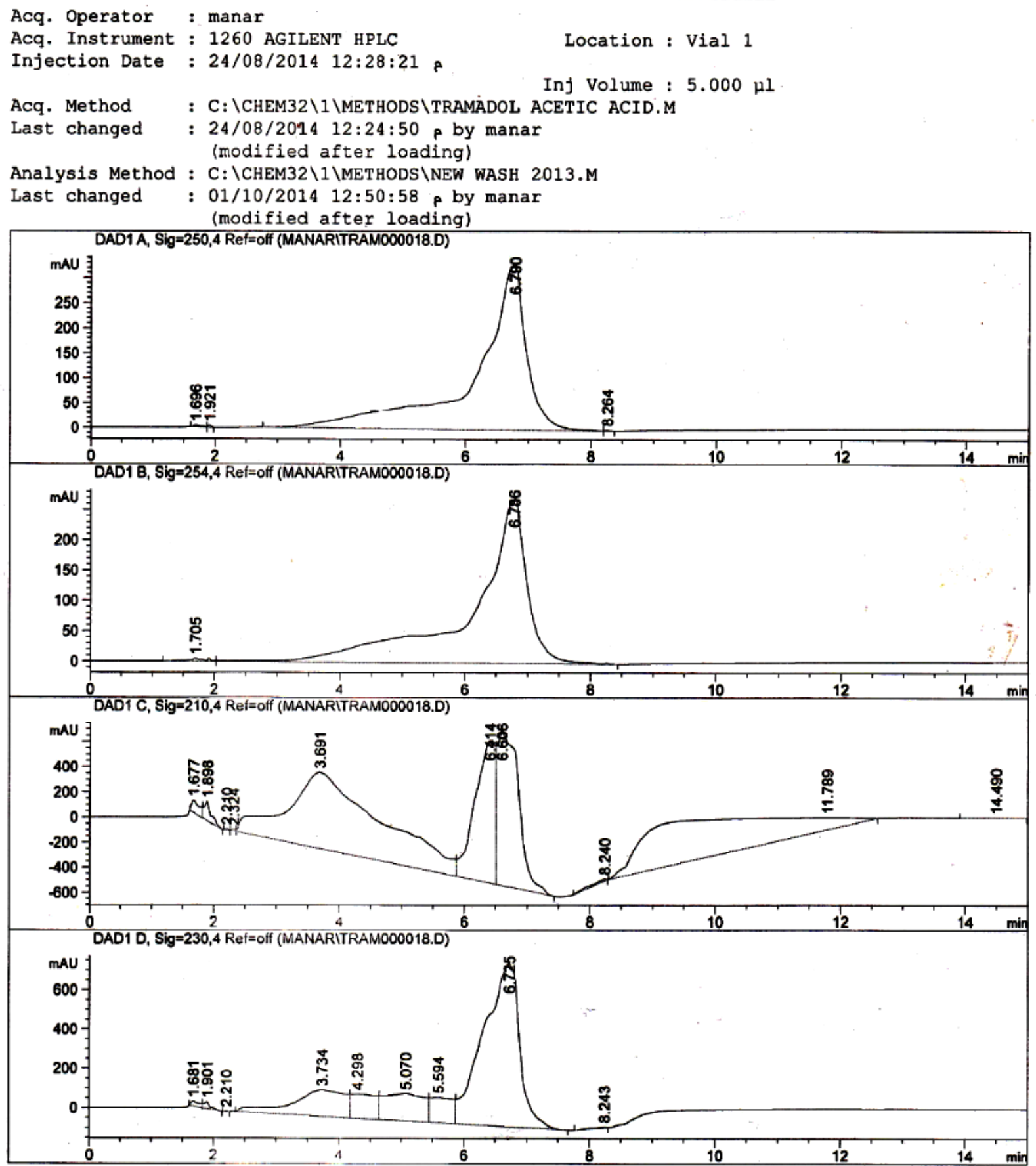

Figure (3): Confirmation of positive TLC results was accomplished by an HPLC technique for tramadol. It was separated and eluted from the column at 6.7 minutes [retention time] 


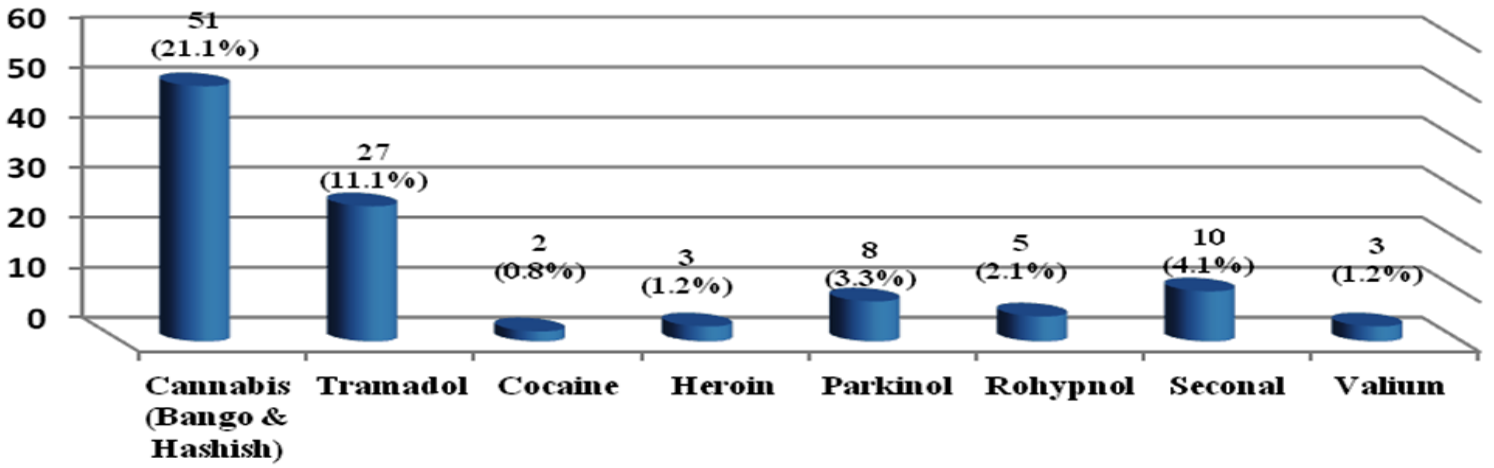

Types of abused substance

Figure (4): Types of abused substance among adults attending the Family Medicine Center of Fanarah Village in Ismailia city, Egypt documented by TLC and HPLC evaluation $(n=109$ of 243$)$.

Table (2): Circumstances of Bango, Hashish and Tramadol abuse among adults attending the family medicine center of Fanarah village in Ismailia city and mentioned their abuse in questionnaires

\begin{tabular}{|c|c|c|c|c|}
\hline \multicolumn{2}{|c|}{$\begin{array}{l}\text { Circumstances of abuse of } \\
\text { Bango, Hashish and Tramadol }\end{array}$} & $\begin{array}{l}\text { Bango }(\mathbf{n}=\mathbf{2 7}) \\
\mathrm{n}(\%)\end{array}$ & $\begin{array}{l}\text { Hashish }(\mathbf{n}=\mathbf{2 0}) \\
\mathrm{n}(\%)\end{array}$ & $\begin{array}{l}\text { Tramadol }(\mathbf{n}=\mathbf{2 4}) \\
\mathrm{n}(\%)\end{array}$ \\
\hline \multirow{4}{*}{$\begin{array}{l}\text { Route of } \\
\text { administration }\end{array}$} & Ingestion & 0 & $2(10)$ & $24(100.0)$ \\
\hline & Smoking & $27(100.0)$ & $11(55.0)$ & 0 \\
\hline & Inhalation \& Smoking & 0 & $6(30.0)$ & 0 \\
\hline & $\begin{array}{l}\text { Inhalation, Smoking } \\
\text { \&Ingestion }\end{array}$ & 0 & $1(5.0)$ & 0 \\
\hline \multirow{5}{*}{$\begin{array}{l}\text { Frequency of } \\
\text { lifetime } \\
\text { substance } \\
\text { abuse }\end{array}$} & $1-5$ & 0 & $1(5.0)$ & 0 \\
\hline & $6-9$ & $1(3.7)$ & $1(5.0)$ & $1(4.2)$ \\
\hline & $10-19$ & $1(3.7)$ & $1(5.0)$ & $2(8.3)$ \\
\hline & $20-39$ & $1(3.7)$ & $1(5.0)$ & $1(4.2)$ \\
\hline & $\geq 40$ & $24(88.9)$ & $16(80.0)$ & $20(83.4)$ \\
\hline \multirow{6}{*}{$\begin{array}{l}\text { Number of } \\
\text { times of abuse } \\
\text { in the last } 12 \\
\text { months }\end{array}$} & None & 2 & 0 & $4(16.6)$ \\
\hline & $1-2$ & 0 & $1(5.0)$ & $1(4.2)$ \\
\hline & $3-5$ & $1(3.7)$ & $3(15.0)$ & 0 \\
\hline & $10-19$ & $1(3.7)$ & $2(10.0)$ & $3(12.5)$ \\
\hline & $20-39$ & $3(11.1)$ & $1(5.0)$ & $1(4.2)$ \\
\hline & $\geq 40$ & $20(74.1)$ & $13(65.0)$ & $15(62.6)$ \\
\hline \multirow{5}{*}{$\begin{array}{l}\text { Time of the } \\
\text { last dose of } \\
\text { drug abused }\end{array}$} & Yesterday & $15(55.6)$ & $5(25.0)$ & $10(41.6)$ \\
\hline & Day before yesterday & $4(14.8)$ & $5(25.0)$ & $2(8.3)$ \\
\hline & 3 days ago & $2(7.4)$ & $5(25.0)$ & $2(8.3)$ \\
\hline & A week ago or more & $4(14.8)$ & $4(20.0)$ & $6(25.0)$ \\
\hline & More than a year & $2(7.4)$ & $1(5.0)$ & $4(16.6)$ \\
\hline \multirow{3}{*}{$\begin{array}{l}\text { Age at first } \\
\text { time of use }\end{array}$} & $15-24$ years old & $16(59.3)$ & $13(65.0)$ & $8(33.3)$ \\
\hline & 25 - 34 years old & $7(25.9)$ & $6(30.0)$ & $15(62.6)$ \\
\hline & $\geq 35$ - years old & $4(14.8)$ & $1(5.0)$ & $1(4.2)$ \\
\hline
\end{tabular}

- Total number of the studied population $(n=243)$

- Adults mentioned their abuse in questionnaires $(n=100)$

- Total positive drug use $(n=109)$ 
Table 3. Circumstances of Cocaine and Heroin abuse among adults attending the family medicine center of Fanarah village in Ismailia city and mentioned their abuse in questionnaires

\begin{tabular}{|c|c|c|c|}
\hline \multicolumn{2}{|c|}{$\begin{array}{c}\text { Circumstances of abuse of } \\
\text { Cocaine and Heroin }\end{array}$} & $\begin{array}{c}\text { Cocaine }(\mathbf{n}=2) \\
\mathrm{n}(\%)\end{array}$ & $\begin{array}{c}\text { Heroin }(\mathbf{n}=\mathbf{3}) \\
\mathrm{n}(\%)\end{array}$ \\
\hline $\begin{array}{c}\text { Route of } \\
\text { administration }\end{array}$ & Inhalation & $\mathbf{2}(\mathbf{1 0 0 . 0})$ & $\mathbf{3}(\mathbf{1 0 0 . 0})$ \\
\hline \multirow{2}{*}{$\begin{array}{c}\text { Time of the last dose of } \\
\text { drug abused }\end{array}$} & A week ago & $\mathbf{0}$ & $\mathbf{1}(\mathbf{3 3 . 3})$ \\
\cline { 2 - 4 } & More than one year ago & $\mathbf{2 ( 1 0 0 )}$ & $\mathbf{2 ( 6 6 . 6 )}$ \\
\cline { 2 - 4 } & Others...... mention & $\mathbf{0}$ & $\mathbf{0}$ \\
\hline $\begin{array}{c}\text { Age at the first time of } \\
\text { use }\end{array}$ & $\mathbf{2 5 - 3 5}$ years old & $\mathbf{1 ( 5 0 . 0 )}$ & $\mathbf{2 ( 6 6 . 6 )}$ \\
\cline { 2 - 4 } & $>35$ years old & $\mathbf{1 ( 5 0 . 0 )}$ & $\mathbf{1 ( 3 3 . 3 )}$ \\
\hline
\end{tabular}

- Participants who used Cocaine and Heroin were not cooperative enough so, there was a shortage of data collected from them.

- Total number of the studied population $(n=243)$

- Adults mentioned their abuse in questionnaires $(n=100)$

- Total positive drug use $(n=109)$

Table (4): Circumstances of Parkinol (saraseer) Rohypnol (abo saleeba) Seconal (farawla) and Valium abuse among adult attending the family medicine center of Fanarah village in Ismailia city and mentioned their abuse in questionnaires.

\begin{tabular}{|c|c|c|c|c|c|}
\hline \multicolumn{2}{|c|}{$\begin{array}{l}\text { Circumstances of abuse of } \\
\text { Parkinol, Rohypnol, Seconal and Valium }\end{array}$} & \multirow{2}{*}{$\begin{array}{l}\begin{array}{l}\text { Parkinol } \\
(\mathbf{n}=\mathbf{6})\end{array} \\
\mathrm{n}(\%) \\
6(100.0)\end{array}$} & \multirow{2}{*}{$\begin{array}{l}\text { Rohypnol } \\
(\mathbf{n}=\mathbf{5}) \\
\text { n }(\%) \\
5(100.0)\end{array}$} & \multirow{2}{*}{$\begin{array}{l}\begin{array}{l}\text { Seconal } \\
(\mathbf{n}=\mathbf{1 0})\end{array} \\
\mathrm{n}(\%)\end{array}$} & \multirow{2}{*}{$\begin{array}{l}\begin{array}{l}\text { Valium } \\
(\mathbf{n}=\mathbf{3})\end{array} \\
\mathrm{n}(\%) \\
3(100.0)\end{array}$} \\
\hline $\begin{array}{l}\text { Route of } \\
\text { administration }\end{array}$ & Ingestion & & & & \\
\hline \multirow{3}{*}{$\begin{array}{l}\text { Frequency of } \\
\text { lifetime substance } \\
\text { abuse }\end{array}$} & $1-5$ & $2(33.3)$ & $2(40.0)$ & $1(10.0)$ & 0 \\
\hline & $6-9$ & $1(16.7)$ & $1(20.0)$ & $1(10.0)$ & $1(33.3)$ \\
\hline & $\geq 10$ & $3(50.0)$ & $2(40.0)$ & $8(80.0)$ & $2(66.7)$ \\
\hline \multirow{3}{*}{$\begin{array}{l}\text { Number of times } \\
\text { of abuse in the } \\
\text { last } 12 \text { months }\end{array}$} & 0 & $5(83.3)$ & $3(60.0)$ & $4(40.0)$ & $1(33.3)$ \\
\hline & $1-9$ & 0 & $2(40.0)$ & $1(10.0)$ & $1(33.3)$ \\
\hline & $\geq 10$ & $1(16.7)$ & 0 & $5(50.0)$ & $1(33.3)$ \\
\hline \multirow{3}{*}{$\begin{array}{l}\text { Number of times } \\
\text { of abuse /Week in } \\
\text { last } 12 \text { months }\end{array}$} & 0 & $5(83.3)$ & $4(80.0)$ & $4(40.0)$ & 0 \\
\hline & $1-5$ & $1(16.7)$ & $1(20.0)$ & $7(70.0)$ & $2(66.7)$ \\
\hline & $6-10$ & 0 & 0 & $3(30.0)$ & $1(33.3)$ \\
\hline \multirow{4}{*}{$\begin{array}{l}\text { Time of the last } \\
\text { dose of drug } \\
\text { abused }\end{array}$} & Yesterday & 0 & $1(20.0)$ & $1(10.0)$ & $1(33.3)$ \\
\hline & A day before yesterday & 0 & 0 & $2(20.0)$ & $1(33.3)$ \\
\hline & 1week ago or more & $1(16.7)$ & 0 & $2(20.0)$ & $1(33.3)$ \\
\hline & More than a year & $5(83.3)$ & $4(80.0)$ & $5(50.0)$ & 0 \\
\hline \multirow{3}{*}{$\begin{array}{l}\text { Age at the first } \\
\text { time of use }\end{array}$} & $15-24$ years old & $3(50.0)$ & $3(60.0)$ & $5(50.0)$ & 0 \\
\hline & 25-34 years old & $3(50.0)$ & $2(40.0)$ & $3(30.0)$ & $3(100.0)$ \\
\hline & $\geq 35$ & 0 & 0 & $2(20.0)$ & 0 \\
\hline
\end{tabular}

- Total number of the studied population $(n=243)$

- Adults mentioned their abuse in questionnaires $(\mathbf{n}=100)$

- Total positive drug use $(n=109)$ 
Table (5): Circumstances of using different types of drug of abuse among adult abusers attending family medicine center of Fanarah village in Ismailia city and mentioned their abuse in questionnaires $(\mathrm{n}=100)$.

\begin{tabular}{|c|c|c|}
\hline \multicolumn{2}{|c|}{ Circumstances of using different types drug of abuse } & \multirow{2}{*}{$\begin{array}{c}\begin{array}{c}\text { Frequency } \\
\mathrm{n}=100(41.1 \%)\end{array} \\
4(4.0)\end{array}$} \\
\hline \multirow{3}{*}{ Smoke Tobacco } & Non smoker & \\
\hline & Ex-smoker & $23(23.0)$ \\
\hline & Smoker & $73(73.0)$ \\
\hline \multirow{2}{*}{ Alcohol } & Yes & $32(32.0)$ \\
\hline & No & $68(68.0)$ \\
\hline \multirow{2}{*}{$\begin{array}{l}\text { Other family members } \\
\text { using drugs }\end{array}$} & Yes & $59(59.0)$ \\
\hline & No & $41(41.0)$ \\
\hline \multirow{4}{*}{$\begin{array}{c}\text { First one who } \\
\text { introduce you these } \\
\text { drugs }\end{array}$} & Friend & $53(53.0)$ \\
\hline & Siblings & $7(7.0)$ \\
\hline & Relatives & $31(31.0)$ \\
\hline & Husband & $9(9.0)$ \\
\hline \multirow{4}{*}{$\begin{array}{c}\text { If drug use affect } \\
\text { your ability to cope } \\
\text { with school or } \\
\text { work }\end{array}$} & Frequently & $22(22.0)$ \\
\hline & Occasionally & $14(14.0)$ \\
\hline & Rarely & $17(17.0)$ \\
\hline & Never & $47(47.0)$ \\
\hline \multirow{4}{*}{$\begin{array}{l}\text { If drug use caused } \\
\text { you problems with } \\
\text { others }\end{array}$} & Frequently & $12(12.0)$ \\
\hline & Occasionally & $16(16.0)$ \\
\hline & Rarely & $16(16.0)$ \\
\hline & Never & $56(56.0)$ \\
\hline \multirow{4}{*}{$\begin{array}{l}\text { Spending time with } \\
\text { friends who use } \\
\text { drug }\end{array}$} & Frequently & $72(72.0)$ \\
\hline & Occasionally & $15(15.0)$ \\
\hline & Rarely & $7(7.0)$ \\
\hline & Never & $6(6.0)$ \\
\hline \multirow{5}{*}{$\begin{array}{l}\text { Reasons for using } \\
\text { illicit drugs }\end{array}$} & Had bad company & $29(29.0)$ \\
\hline & One of the parents or family members used it & $36(36.0)$ \\
\hline & Just for fun & $12(12.0)$ \\
\hline & A tragic event had happened in my life & $14(14.0)$ \\
\hline & Curiosity to experience it & $9(9.0)$ \\
\hline
\end{tabular}

Data are expressed as $n$ ( $\%$ of one hundred participants).

\section{DISCUSSION}

Illicit drug use has grown to such proportions that they have become priority health problems and a serious threat to the stability of social, political and legal institutions in many countries (Fawzi, 2011).

In the current study, an anonymous questionnaire was filled from all participants by the researchers. Due to its anonymity, it could be, possibly, the optimum way to collect information about personal behavior, although careful attention must be given to the validity and reliability of responses (Corti et al., 2000).

In the present study it was found that, $44.8 \%$ of all participants had experienced illicit drug use documented by TLC and HPLC investigations; this finding was in agreement with either increases of drug use trend or continues to be stable noted over the past four years in Egypt 
(Egyptian Gazette, 2011; Hamdi et al., 2013; Loffredo et al., 2015), who reported that, youth in Egypt had an entry to substances faced in similar research worldwide, including tobacco, alcohol, using illicit drugs, cigarettes smoking, abuse of cannabis and tramadol which were commonly used among $14.3 \%$ of adults, and around the world (Martins, et al., 2015; Tulloch et al., 2012; UNODC, 2016). There also seems to be a considerable farming of cannabis in the Sinai Peninsula bypassing to the rest of Egypt through Sharkia, Ismailia, and Suez (United Nations Office for Drug Control and Crime Prevention, 2009). The regional cannabis output and the nomad inter tribal lifestyle of persons with Bedouin ancestry might clarify the elevation of illicit drug use rate discovered in this work.

It was notable that there were some differences between the percentages of the questionnaire results and that of the urine-based test results. Nine participants more than those mentioned that they were drug abusers have been documented by TLC and HPLC investigations. This could be attributed to various factors including; fear of the social stigma of illicit drug use, particularly in participants who had negative answers regarding abusing cannabis and tramadol in the questionnaire, but their urine specimens revealed positive results. In addition, each drug has a detection time (ranging from 48 hours in some drugs to 45 days in others; as in the case for cannabis) (Ellis et al., 1985). The substance tetrahydrocannabinol (THC) has high lipid solubility, resulting in extensive storage of the drug in the lipid compartments of the body. This lipid solubility is associated with slow excretion of the drug and its metabolites in the urine. A single use of marijuana can result in positive urine tests up to one week after administration; whereas long-term use can produce positive results in the urine up to 46 days after cessation (Moeller et al., 2008). This duration might be preceded in a number of the participants, which resulted in positive results in the urine, although they stated that, they didn't take the substance many weeks previously. The mental state of the abusers (as confusion), in addition, should be considered which might be responsible for their inaccurate answers to the questionnaire.

Thirty nine illicit drug users (16.0\%) of the total adult participants in the current study were of age group 19-25 years. This result seems to be different from that reported by Atwoli et al., (2011), who found about $69.8 \%$ of college and University students in the Eldoret Municipality in Western Kenya were using illicit drugs. This variation might be attributed to the difference in the age group of the studied populations, where drug use is more common among young people in college than other adult population. In addition, this variation, might be due to the difference of cultures between the studied populations, together with more availability of drugs in this part of Africa.

Age of using first drug is an additional important risk factor for later dependence and experimentation with other drugs (Vega et al., 2002). In the current study, the majority of drug abusers started taking drugs for the first time at age 15-24 years old. This was clearly obvious in cannabis abusers; with a percentage of $59.3 \%$ and $65.0 \%$ for Bango and Hashish abusers, 
respectively. This finding was in line with Meyers and Dick, (2010), who reported that initiation into cannabis use typically begins in adolescence, as youths aged 12 to 17 years constitute about two-thirds of the new cannabis users and this could predispose to cannabis dependence at a rate roughly twice that reported for adult-onset users. On the other hand, those who abuse Heroin and Cocaine in the current study, started their abuse after the age of 25 years.

Concerning the gender of illicit drug users, the number and percentage of the gender were representing 80 males $(32.9 \%)$ to 29 females (11.9\%) of all participants. This finding was in congruence with Mariana et al., (2008) and El-Sawy et al., (2010), who found that although tranquilizers and barbiturates were particularly popular among females, males abuse drugs more commonly than females. The latter authors carried out their work on four hundred and fifty seven patients of drug dependence who attended outpatient clinics of the Neuropsychiatry department in Tanta University hospital, Egypt between the period from June 2006 to June 2009. They concluded that males started drug use earlier than females and had a longer duration of dependence compared to females, and males abuse drugs more commonly than females (El-Sawy et al., 2010). Illicit drug use is uncommon among Egyptian women as using of entry substances as tobacco in females is correlated with social stigma. In addition, there is a considerable degree of limitation on the woman performance. In spite of this low prevalence, the tendency for substance abuse in Egyptian women is increasing (Goreishi \& Shajari, 2013; Okasha, 2004).

Most substance users were resident in urban areas, and this finding was in partial agreement with Hamdi et al., (2013), findings who reported a small urban/rural variation in illicit drug use levels, with urban rates greater as expected. However, a previous study with comparable findings across England reported rural urban differences. Urban studies included large metropolitan areas and reported urban rates higher of drug users in comparison to the rural areas (Holland et al., 2006).

Those who ever married were found to have a higher prevalence of abusing drugs with $21.3 \%$ compared to $18.1 \%$ among single ones. This figure was less than reported by El-Sawy et al., (2010), who conducted their work in another area of Egypt and found that of 457 addicts, married abusers represented $49.0 \%$ of the studied group. This difference could be attributed to either the relatively small representation of the single population in the current study $(35 \%)$, or it might be related to the drugs alleged enhancement of sexual performance.

Concerning the education, the current study showed that, highly educated participants (high school and University level), $24.3 \%$ mentioned their illicit drug use in questionnaires, $0.8 \%$ denied their illicit drug use, $24.3 \%$ have skilled jobs and $6.2 \%$ were unemployed. This result was partially in agreement with Shalaby et al., (2015), who reported that, nearly $48 \%$ of tramadol addicts completed either technical education or high school, while $27 \%$ graduated from college and $16.6 \%$ were unemployed. 
In addition, the current study found that nearly half of the unemployed adults, and those with skilled jobs were found to use illicit drugs, representing $7.0 \%$ and $27.1 \%$ of the abusers, respectively. It was also found that, about $11.0 \%$ of all studied population who had specialized jobs were found to abuse the drugs. On the other hand, a national study was carried out on U.S. by Frone, (2006), found that about 56 $\%$ of young men in high-risk occupations reported using illicit drugs from whom $28 \%$ used it in the workplace. Also, the study of Fawzi, (2011), which was carried out to investigate some medicolegal aspects concerning tramadol abuse in Egypt, mentioned that being unemployed was a factor for most of tramadol addicts.

Almost $26.3 \%$ of all participants were abusers and stated that their income was inadequate, while $18.5 \%$ had adequate income. This may be in partial agreement with Ellickson et al., (1997), who reported that poverty could be a contributing factor of drug trading and abuse in different societies. However, the slight difference in percentages between the sufficient and insufficient income groups might predict that no social class is spared when concerning the drug issue. This finding is consistent with Patrick et al., (2012), who concluded from their work on the data obtained from the national Panel Study of Income Dynamics of U.S., association of smoking in young adulthood with lower childhood family socioeconomic status, while alcohol use and marijuana use in young adulthood were associated with a higher one, even after controlling for covariates.

In terms of drug use pattern among abusers, the present study revealed that cannabis in two forms, Bango and Hashish $(21.1 \%)$ and tramadol (11.1\%) were the most commonly abused drugs, followed by barbiturates with percentage of $4.1 \%$ (in the form of Seconal) and Parkinol (3.3\%). Abusing Heroin, Cocaine and Valium was less prevalent among the studied adults $(1.2 \%, 0.8 \%$ and $1.2 \%$, respectively). These results were incongruent with results published by Mariana et al., (2008), where cannabis, medicinal products in the form of barbiturates, antihistaminic and tranquilizers were the most prevalent drugs, while cocaine and heroin were less prevalent . Based on urine screening test among permanent hired hospital cleaners, Fawzi, (2011), reported positive results for cannabis $(24.4 \%)$, tramadol (20.6 $\%)$ and amphetamines $(0.96 \%)$, while it showed negative results for cocaine and barbiturates. On the other hand, the current findings didn't agree with that reported by Okasha, (2004), where the most commonly used drugs were cannabis, opium, solid and liquid hypno-sedatives, heroin and finally cocaine, in descending order of frequency. This dissimilarity could be due to the different time in which the two studies took place, where there was a difference in the availability of drugs and also, this might indicate that new drugs were emerging.

In the current study, Bango and Hashish users represented $11.1 \%$ and $8.2 \%$, respectively; this result mentioned by participants during fulfillment the questionnaires. It is worth mentioning that cannabis were found to be the most common drugs abused in many studies conducted on different age groups in different countries (Health \& Social Care Information Centre, 2016; Johnston 
et al., 2013; Odek-Ogunde \& PandeLeak, 1999), even among the families and friends of the studied population. This is also coinciding with the results of the World Drug Report, (2012), which found that cannabis remains the world's most widely used illicit substance. However, in the last few years, tramadol abuse became also a critical phenomenon in Egypt (Fawzi, 2011). It has been found to be commonly used among abusers in their life $(11.1 \%)$ in the current study. Nearly 320 million tramadol tablets were seized in the first quarter of 2012 (United Nations, 2013). It became the most commonly abused drug among young and the middle-aged because it is readily available in the black market, can be supplied at low cost, and is a good medicament for premature ejaculation (Fawzi, 2011; Salem et al. 2008).

\section{CONCLUSIONS \& RECOMMENDATIONS}

Illicit drug use among adults in the study population starts in younger ages. Cannabis is still the most widely abused one, although tramadol becomes an increasingly alarming phenomenon. The success of the efforts attempt at curbing illicit drug use among youth depends on the presence of a united strategy in terms of laws, government policies, and participation of civil society and the media. The presence of a specialized center in the Suez Canal Area is important to treat illicit drug users and their families. We recommend that doctors and nurses of the Suez Canal area should be able to deal with illicit drug users with the presence of trained staff's psychological support, abusers will be encouraged to go to this center instead of regular police stations and will be ensured confidentiality.

\section{Limitations:}

One of the main limitations of this study was the cross sectional nature of the research design; so, the results did not capture changes in the illicit substance pattern of use over time. In addition, adults who were not attending the family center at the time of the study were not able to participate. Despite these limitations، the study findings point to important areas of need for implementing condensed educational and screening strategies to overcome the current substance misuse.

\section{Declaration of Interest}

The authors report no conflicts of interest. The authors alone are responsible for the content and writing of the article.

\section{Glossary}

Drug dependence: A maladaptive pattern of illegal drug use (including marijuana or hashish) and/or nonmedical use of prescription drugs as manifested by at least three symptoms of dependence occurring at any time in the same 12-month period (i.e., tolerance, withdrawal, increased consumption, attempts to quit, time lost, reduced activities, and continued drinking.

Substance dependence: Either alcohol and/or drug dependence, as defined above.

Hashish: A cannabis product composed of compressed or purified preparations of cannabinoid-rich glandular hairs known as trichomes. It contains higher concentrations of active ingredients, including THC and other cannaboids, compared with unsifted cannabis buds or leaves.

Tramadol: An opioid that was first synthesized in Germany in 1962 and 
has been available for pain treatment since 1977. It is sold under additional trade names such as Tamol, Ultradol, Tramidine, and Tramal.

\section{REFERENCES}

Atwoli, L.; Mungla, PA.; Ndung'u, MN.; Kinoti, K.C. and Ogot, EM. (2011): Prevalence of substance use among college students in Eldoret, western Kenya. BMC Psychiatry, 11: 34 .

Bassiony, M.M.; Salah El-Deen, G.M.; Yousef, U.; Raya, Y.; AbdelGhani, M. M. and Atwa, S.A. (2015): Adolescent tramadol use and abuse in Egypt. Am J Drug Alcohol Abuse, 2015;(41), 206-11.

Charlson, F.J.; Baxter, A.J.; Dua, T.; Degenhardt, L.; Whiteford, H.A. and Vos, T. (2015): Excess Mortality from Mental, Neurological, and Substance Use Disorders in the Global Burden of Disease Study 2010. Epidemiol Psychiatr Sci, 24, 121-140.

Corti, L.; Day, A. and Backhouse, G. (2000): Confidentiality and Informed Consent: Issues for Consideration in the Preservation of and Provision of Access to Qualitative Data Archives [46 paragraphs]. Forum Qualitative Sozialforschung / Forum: Qualitative Social Research, 1(3).

Darke, S.; Degenhadt, L. and Mattick, R. (2006): The global epidemiology of illicit drug use. In Mortality amongst illicit drug users: Epidemiology, Causes and Intervention. Cambridge University Press, pp. 10-19

Degenhardt, L. and Hall, W. (2012): Extent of illicit drug use and dependence, and their contribution to the global burden of disease. The Lancet, 379, 55-70.

Egyptian Gazette. (2011): Drug abuse in Egypt on the rise. Retrieved from http://www.masress.com/en/egyptian gazette/19958

Ellickson, P.; Saner, H. and McGuigan, K.A. (1997): Profiles of violent youth: substance use and other concurrent problems. Am J Public Health, 87, 985-991. https://www.ncbi.nlm.nih.gov/pmc/a rticles/PMC1380935/

Ellis, G.M.; Mann, M.A.; Judson, B.A.; Schramm, N.T. and Tashchian, A. (1985): Excretion patterns of cannabinoid metabolites after last use in a group of chronic users. Clin Pharmacol Ther, 38, 572578.

El-Sawy, H.; Abdel Hay, M. and Badawy, A. (2010): Gender differences in risk and pattern of drug abuse in Egypt. Egypt $\mathbf{J}$ Psychiat Neurosurg, 47, 413-418. http://ejnpn.org/articles/585/201047 3011.pdf

Fawzi, M.M. (2011): Medicolegal aspects concerning tramadol abuse: The new Middle East youth plague: An Egyptian overview 2010. Egyptian Journal of Forensic Sciences, 1, 99-102. http://dx.doi.org/10.1016/j.ejfs.2011. 04.016

Frone, M.R. (2006): Prevalence and distribution of illicit drug use in the workforce and in the workplace: Findings and implications from a U.S. National survey. Journal of Applied Psychology, 91, 856-869.

Goreishi, A. and Shajari, Z. (2013): Substance Abuse among Students of Zanjan's Universities (Iran): A Knot of Today's Society. Addiction \& Health, $\quad 5, \quad 66-72$. 
https://www.ncbi.nlm.nih.gov/pmc/a rticles/PMC3905561/

Hamdi, E.; Gawad, T.; Khoweiled, A.; Sidrak, A.; Amer, D.; Mamdouh, R. and Loza, N. (2013): Lifetime Prevalence of Alcohol and Substance Use in Egypt: A Community Survey. Substance Abuse, 34, 97-104.

Health and Social Care Information Centre (hscic). (2016): Statistics on Drug Misuse: England 2016. Retrieved from http://content.digital.nhs.uk/catalogu e/PUB21159/drug-misu-eng-2016rep.pdf

Holland, R.; Vivancos, R; Maskrey, V.; Sadler, J.; Rumball, D.; Harvey, I. and Swift, L. (2006): The prevalence of problem drug misuse in a rural country of England. J Public Health (Oxf), 28, 88-95.

Johnston, L.D.; O'Malley, P.M.; Bachman, J.G. and Schulenberg, J.E. (2013): Monitoring the Future national results on drug use: 2012 Overview, Key Findings on Adolescent Drug Use. Ann Arbor: Institute for Social Research, The University of Michigan. Retrieved from

http://monitoringthefuture.org/pubs/ monographs/

Khalsa, J.H.; Treisman, G.; McCanceKatz, E. and Tedaldi, E. (2008): Medical Consequences of Drug Abuse and Co-occurring Infections: Research at the National Institute on Drug Abuse. Substance Abuse: Official Publication of the Association for Medical Education and Research in Substance Abuse, 29, 5-16.

Loffredo, C.A.; Boulos, D.N.; Saleh, D.A.; Jillson, I.A.; Garas, M.;
Loza, N. and Amr, S. (2015): Substance Use by Egyptian Youth: Current Patterns and Potential Avenues for Prevention. Substance Use \& Misuse, 50, 609-618.

Mariana, M.; Aimee, N.; Tarek, A.; Leen, A.; Zeina, N. and Elie, G. (2008): Epidemiologic Assessment of Substance Use in the Arab World. The Arab Journal of Psychiatry, 19, 100125.

http://arabjournalpsychiatry.com/wp content/uploads/2015/12/

Martins, S.S.; Sampson, L.; Cerdá, M. and Galea, S. (2015): Worldwide Prevalence and Trends in Unintentional Drug Overdose: A Systematic Review of the Literature. American Journal of Public Health, 105, 29-49. http://doi.org/10.2105/AJPH.2015.3 02843

McIntosh, J.; MacDonald, F. and McKeganey, N. (2006): Why do children experiment with illegal drugs? The declining role of peer pressure with increasing age. Addiction Research \& Theory, 14, 275-287.

Meyers, J.L. and Dick, DM. (2010): Genetic and Environmental Risk Factors for Adolescent-Onset Substance Use Disorders. Child and Adolescent Psychiatric Clinics of North America, 19, 465-477. http://doi.org/10.1016/j.chc.2010.03. 013

Moeller, K.E.; Lee, K.C. and Kissack, J.C. (2008): Urine Drug Screening: Practical Guide for Clinicians. Mayo Clin Proc, 83, 66-76.

Nickerson, B. (2011): Sample Preparation of Pharmaceutical Dosage Forms: Challenges and Strategies for Sample Preparation and Extraction, 41-59. 
Odek-Ogunde, M. and Pande-Leak D. (1999): Prevalence of substance use among students in a Kenyan University: a preliminary report. East Afr Med J, 76, 301-6. https://www.ncbi.nlm.nih.gov/pubm ed/10750515

Okasha, A. (2004): Focus on psychiatry in Egypt. BJPsych, 185, 266-272.

Patrick, M.; Wightman, P.; Schoeni, R.F. and Schulenberg, J.E. (2012): Socioeconomic Status and Substance Use Among Young Adults: A Comparison Across Constructs and Drugs. J Stud Alcohol Drugs, 73, 772-782.

Salem, E.A.; Wilson, S.K.; Bissada, N.K.; Delk, J.R.; Hellstrom, W.J. and Cleves, M.A. (2008): Tramadol HCL has promise in on-demand use to treat premature ejaculation. J Sex Med, 5, 188-193.

Shalaby, A.S.; El-Hady, O.A. and Ads, M.K. (2015): Does Tramadol Increase the Severity of Nicotine Dependence? A Study in an Egyptian Sample. J Psychoactive Drugs, 47, 197-202.

Shankaran, S.; Lester, B.M.; Das, A.; Bauer, C.R.; Bada, H.S.; Lagasse, L. and Higgins, R. (2007): Impact of maternal substance use during pregnancy on childhood outcome. Semin Fetal Neonatal Med 12, 143150.

Solomon, W.D.; Anand, P.R.; Shukla, R.; Sivakumar, R. and Venkatnarayanan, R. (2010): Application of TLC- Densitometry Method for Simultaneous Estimation of Tramadol $\mathrm{Hcl}$ and Paracetamol in Pharmaceutical Dosage Forms. Int J
ChemTech Res, 2, 1188-1193. http://connection.ebscohost.com/c/ar ticles/51924426/

Tulloch, A.D.; Frayn, E.; Craig, T.K. and Nicholson, T.R. (2012): Khat use among Somali mental health service users in South London. Social psychiatry and psychiatric epidemiology, 47, 1649-1656.

United Nations Office for Drug Control and Crime Prevention. Country Profile, Egypt. 2009:.

United Nations Office on Drugs and Crime (UNODC). (2012): World drug report 2012. Retrieved from http://www.unodc.org/unodc/en/data -and-analysis/WDR-2012.html

United Nations Office on Drugs and Crime (UNODC). (2016): Illicit drug markets: situation and trends. Retrieved from http://www.unodc.org/doc/wdr 2016/ .

United Nations. (2013): Report of the International Narcotics Control Board for 2012. Vienna: International Narcotics Control Board, January 2013:

Vega, W.A.; Aguilar-Gaxiola, S.; Andrade, L.; Bijl, R.; Borges, G.; Caraveo-Anduaga, J.J. and Wittchen, H.U. (2002): Prevalence and age of onset for drug use in seven international sites: results from the international consortium of psychiatric epidemiology. Drug and alcohol dependence, 68, 285-97.

World Health Organization (WHO) (2013): Health topics, substance abuse,

http://wwwwhoint/topics/substance abuse/en/ 


\section{نمـط تـعاطي المخدرات بيـن الكبـار المتردديـن على مـركز طب الأسـرة بـقرية فنـارة} - بمحسفظة الإســـاعيليـةــ مصـر

صفاء محمد الزغبى'، نادية مبروك' ،ناهد الدهشان' ،منال سعيد فوزى'، عبير محمد هجرس"r 'قسم طب الأسرة ، ‘َقم الكيمياء الحيوية ، "َقسم الطب الثرعى والسموم الأكلينيكية

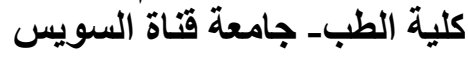

يختلف نمط تعاطي و ادمان المخدرات بين البلدان. و هذا النمط جدير بالإهتمام لتحقيق أفضل النتائج عند

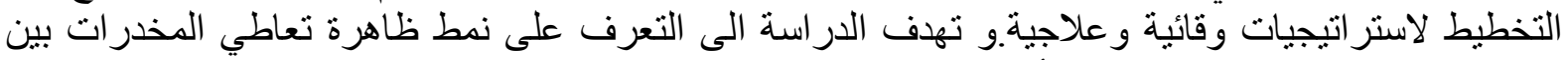

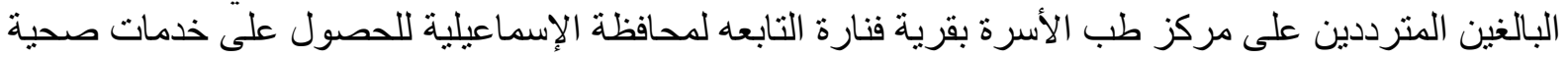
مختلفة.

و قد أجريت دراسة وصفية مقطعية على مائتين ثلاثة واربعين من البالغين الذين يترددون على مركز

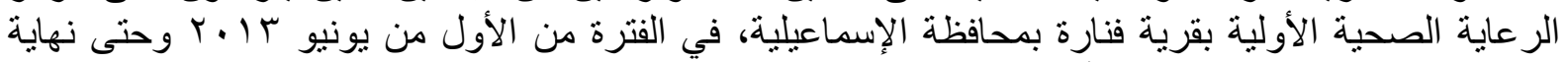

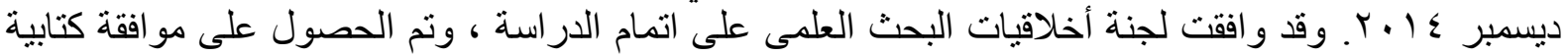

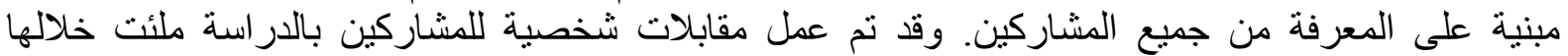

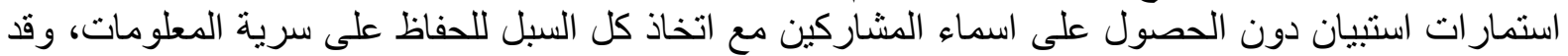

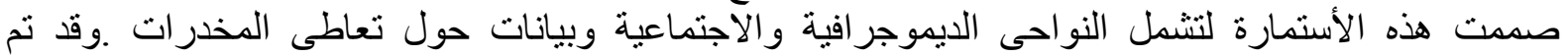

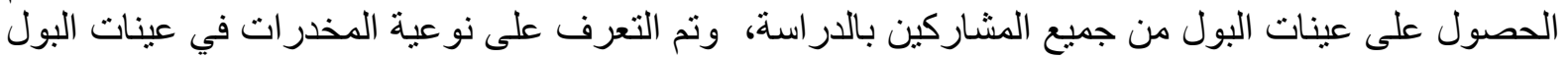

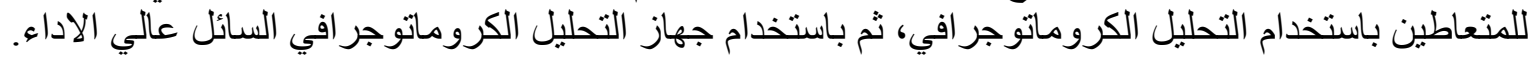

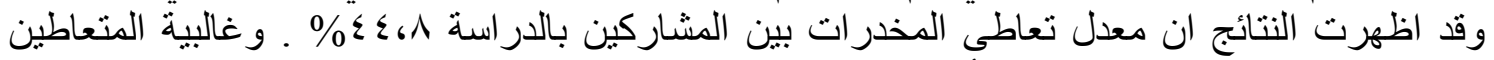

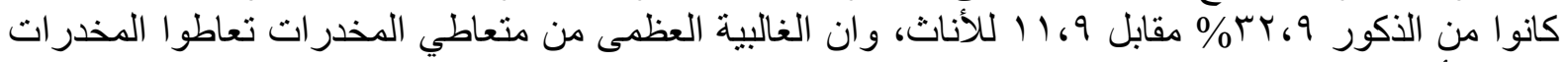

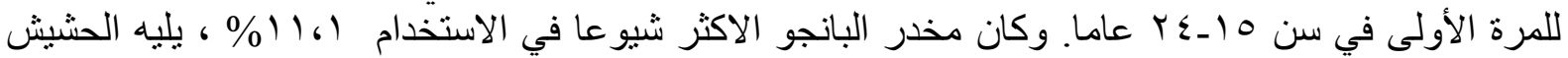

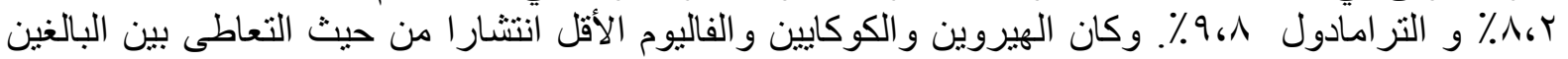

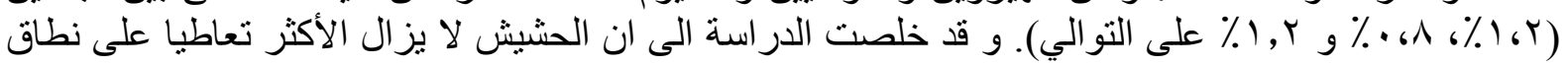

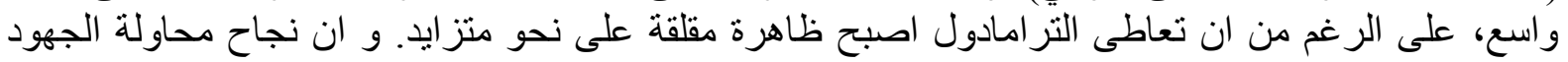

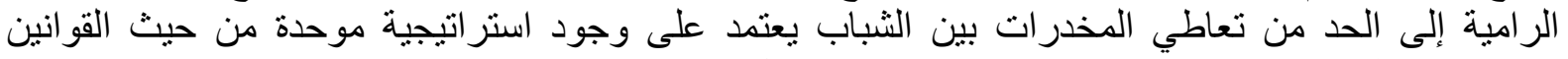

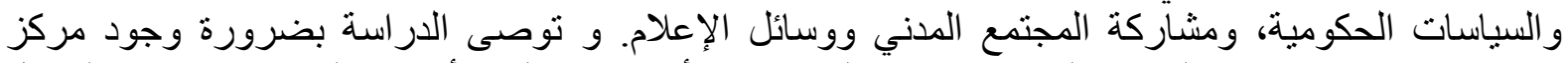

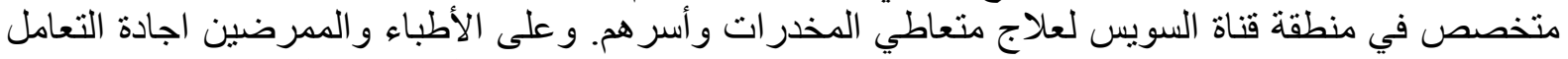

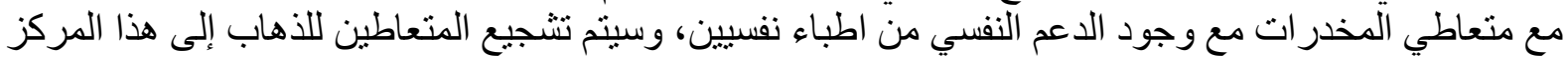
بدلا من مر اكز الثرطة مع ضعمان السرية. 